\title{
The Puzzle of Positive Results - Myocardial Revascularization
}

\section{Citation}

Jones, David S. 2015. “The Puzzle of Positive Results - Myocardial Revascularization." New England Journal of Medicine 372 (6) (February 5): 501-503. doi:10.1056/nejmp1414157.

\section{Published Version}

doi:10.1056/NEJMp1414157

\section{Permanent link}

http://nrs.harvard.edu/urn-3:HUL.InstRepos:30780171

\section{Terms of Use}

This article was downloaded from Harvard University's DASH repository, and is made available under the terms and conditions applicable to Other Posted Material, as set forth at http:// nrs.harvard.edu/urn-3:HUL.InstRepos:dash.current.terms-of-use\#LAA

\section{Share Your Story}

The Harvard community has made this article openly available.

Please share how this access benefits you. Submit a story.

\section{Accessibility}




\section{The Puzzle of Positive Results - Myocardial Revascularization}

The coronary-sinus reduction described by Verheye et al. in this issue of the Journal (pages 519-527) revives an old therapeutic concept. Between 1948 and 1968, Cleveland surgeon Claude Beck performed coronary-sinus ligation in more than 1000 patients, aiming to improve myocardial oxygenation. Despite Beck's reports of impressive efficacy, few surgeons adopted his techniques. The history of this procedure and of other abandoned techniques of myocardial revascularization provides invaluable perspective on continuing efforts to treat coronary artery disease (CAD).

As CAD's prevalence increased in the early 20th century, physicians pursued it aggressively, using an astonishing range of surgical procedures. The common understanding of CAD as a mismatch between oxygen supply and demand suggested two basic strategies: increase blood flow to the heart or reduce demand for it. Some surgeons reduced myocardial oxygen demand by disrupting sympathetic innervation to the heart through sympathectomy or alcohol injection (1924, 1926, 1929; see box for historical references in the Journal). Others reduced metabolic activity with thyroidectomy (1933). Surgeons also tried to bring new blood to the heart by ligating the internal thoracic arteries to shunt blood through pericardiophrenic collaterals (1957a, 1959) or by implanting the internal thoracic arteries into the myocardium (1957b).

Beck's work was particularly innovative. Beginning in 1932, he created "extracoronary communications" by abrading the epicardium with a burr and by grafting pericardium, thoracic muscles, lung, diaphragm, stomach, spleen, omentum, or mediastinal fat onto its surface..$^{1,2}$ Simply increasing supply was not enough. Beck believed that coronary occlusions created patchy myocardial ischemia. The juxtaposition of adequately and inadequately oxygenated tissue produced an electrical imbalance, "an irritable focus," that triggered ventricular fibrillation ${ }^{1}$ the heart, in effect, "electrocutes itself" (1960). To ensure an even distribution of blood, Beck elicited "intercoronary communications" by dusting the heart with irritants to create vascularized scar tissue. ${ }^{1}$ He tested powdered beef bone, iron filings, formaldehyde, horse serum, and dried, sterilized, human skin, but "powdered asbestos produced the most desirable result."

Other surgeons reengineered the heart's venous drainage to improve myocardial oxygenation, inspired by the observation that angina often disappeared with right-sided heart failure. ${ }^{3} \mathrm{Had}$ increased venous pressure somehow improved myocardial perfusion? Could the same effect be achieved by ligating the coronary sinus? In 1935, Louis Gross and colleagues in New York proposed that such ligation would dilate existing intracoronary collaterals. In experiments in animals, sinus ligation produced "a rapid increase in the extent of the coronary bed." 3 Partial ligation protected dogs against subsequent occlusion of their coronary arteries. $^{2,3}$ The exact physiological mechanism was never clear. Beck speculated that venous congestion allowed the myocardium to extract more oxygen or minimized the oxygen differentials that produced fibrillating currents. ${ }^{4}$

World War II put Beck's research on hold, but afterward he returned to myocardial revascularization and by 1955 had developed two distinct operations. ${ }^{2}$ One involved placing a bypass graft between the aorta and the coronary sinus, arterializing the vein, and then partially ligating the distal sinus. Despite good laboratory results, Beck abandoned this procedure because of unacceptable mortality ( $>25 \%$ ) among patients. The other operation combined partial ligation of the coronary sinus with abrasion of the epicardium, application of asbestos powder, and grafting of mediastinal fat. ${ }^{4,5}$ This procedure provided a modest increase in blood flow and, more important, ensured more uniform perfusion, reducing the risk of "selfelectrocution." ${ }^{\prime 4}$

Results were gratifying. Beck reported that $32 \%$ of 295 survivors studied were "completely or almost completely free of pain and have taken no medicaments since operation." Another 62\% had only occasional pain. ${ }^{4}$ Patients who'd been incapacitated before surgery resumed their previous jobs or engaged in "some kind of gainful work." Eleven of 13 had significant improvement on ballistocardiography; 17 of 20 gained relief from "distressing and alarming" arrhythmias. Surgery im- 


\section{Historical Journal Articles Cited.}

The Boston Medical and Surgical Journal

1924. The surgical treatment of angina pectoris. 191:1183-4.

1926. White PD, Richardson EP. Sympathectomy for angina pectoris in a woman of twenty-two. 194:790-5.

\section{The New England Journal of Medicine}

1929. Sprague HB, Mixter WJ. A new method for the treatment of severe angina pectoris. 200:199-200.

1933. Levine SA, Cutler EC, Eppinger EC. Thyroidectomy in the treatment of advanced congestive heart failure and angina pectoris. 209:667-79.

1957a. Ligation of the internal mammary arteries. 257:385.

1957b. Vineberg A. Ligation of internal mammary arteries. 257:896.

1958. Longmire WP, Cannon JA, Kattus AA. Direct-vision coronary endarterectomy for angina pectoris. 259:993-9.

1959. Cobb LA, Thomas GI, Dillard DD, Merendino KA, Bruce RA. An evaluation of internal-mammary-artery ligation by a double-blind technic. 260:1115-8.

1960. Beck CS. Re coronary heart disease. 263:414.

1962. Shaw RS. Reconstructive vascular surgery. 266:392-9.

1964. Connolly JE, Eldridge FL, Calvin JW, Stemmer EA. Proximal coronary-artery obstruction: its etiology and treatment by transaortic endarterectomy. 271:213-9.

1966. Gorlin R, Taylor WJ. Selective revascularization of the myocardium by internalmammary-artery implant. 275:283-90.

1967. Braunwald E, Epstein SE, Glick G, Wechsler AS, Braunwald NS. Relief of angina pectoris by electrical stimulation of the carotid-sinus nerves. 277:1278-83.

1970. Cooper GM. Aortocoronary saphenous bypass. 282:456.

1977. Braunwald E. Coronary-artery surgery at the crossroads. 297:661-3.

1979. Grüntzig AR, Senning $\AA$, Siegenthaler WE. Nonoperative dilatation of coronaryartery stenosis. 301:61-8.

1993. Topol EJ, Leya F, Pinkerton CA, Whitlow PL, et al. A comparison of directional atherectomy with coronary angioplasty in patients with coronary artery disease. 329:221-7.

1994. Fischman DL, Leon MB, Baim DS, et al. A randomized comparison of coronary stent-placement and balloon angioplasty in the treatment of coronary artery disease. 331:496-501.

1999. Lange RA, Hillis LD. Transmyocardial laser revascularization. 341:1075-6.

2001. Leon MB, Teirstein PS, Moses JW, et al. Localized intracoronary gammaradiation therapy to inhibit the recurrence of restenosis after stenting. 344:250-6.

2013. Fröbert $O$, Lagerqvist $B$, Olivecrona GK, et al. Thrombus aspiration during ST-segment elevation myocardial infarction. 369:1587-97.

2014. Redberg RF. Sham controls in medical device trials. 371:892-3.

proved skin temperature in 21 of 23 patients who'd had cold feet - "an objective measurement," wrote Beck, "which must be accepted as fact." ${ }^{4}$ Long-term follow-up of 137 consecutive patients revealed mortality of just $13 \%$ rather than the expected $30 \% .^{5}$

Beck's results are puzzling, given the operation used to achieve them. Other early revascularization procedures had similar suc- cess. Boston surgeons implanted internal thoracic arteries in 40 patients between 1964 and 1966. Angina "all but disappeared" in 5 of 20 patients followed for more than 1 year and was "markedly reduced" in 11 (1966). Angiography revealed "distribution of dye throughout all branches" in some patients (1966). Coronary flow, measured with ${ }^{85} \mathrm{Kr}$-tagged saline, and myocardial physiology, as assessed by lactate extraction, improved as well.

These revascularization procedures initially generated enthusiasm. Surveying the field in 1956, one of Beck's collaborators found 50 thoracic surgeons in the United States, and at least another 20 in Europe and Israel, who had attempted surgical repair of coronary disease in a total of more than 1200 patients. ${ }^{5}$ A 1957 editorial declared that these efforts "have placed the myocardium in a class by itself as an object of surgical assault" (1957a). However, none of these operations saw "wide general use." 2 While just hundreds of patients underwent surgery for CAD each year in the late 1950s, hundreds of thousands died from it.

The situation, however, changed quickly. Guided by coronary angiography, surgeons and then interventional cardiologists developed many more techniques. Over the years, Journal readers were informed about coronary endarterectomy (1958), patch-graft reconstruction (1962), transaortic endarterectomy (1964), carotidsinus stimulation (1967), coronaryartery bypass grafting (1970, 1977), balloon angioplasty (1979), atherectomy (1993), coronary stents (1994), transmyocardial laser revascularization (1999), intracoronary gamma radiation (2001), and thrombus aspiration (2013).

How does this history help us understand the current report? The new coronary-sinus reducer bears little resemblance to Beck's techniques. Beck performed a thoracotomy to place a $3-\mathrm{mm}$ diameter loop around the sinus, combining that with abrasion, asbestos, and grafting. ${ }^{4}$ Verheye et al. pursued the same physiological outcome more benignly, through endovascular insertion of a flow-limiting stent. Beck urged 


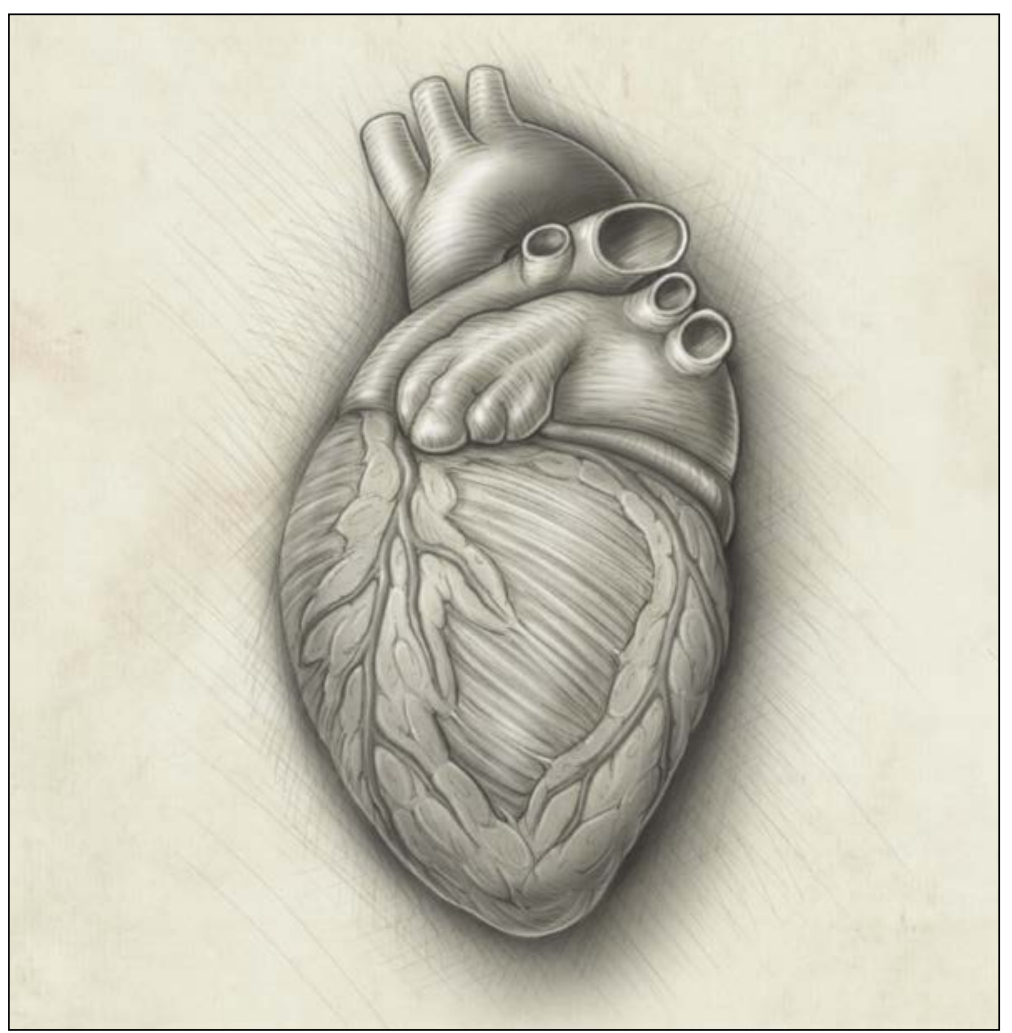

surgeons to operate early, because "advanced disease is practically hopeless from the surgical point of view." Verheye and colleagues reserved sinus reduction for the sickest patients, who were not candidates for angioplasty and bypass surgery. Nonetheless, the history offers important lessons.

First, physicians have been remarkably ingenious in designing interventions against $\mathrm{CAD}$ and startlingly willing to try them in patients, despite uncertain physiological rationales. Internal-thoracic-artery ligation generated excitement in 1957 even though the Journal deemed it the "most implausible operation of all" (1957a). Montreal cardiac surgeon Arthur Vineberg dismissed skeptics who feared that artery implants would simply produce intramyocardial hematomas (1957b). ${ }^{2}$ Early advocates of balloon angioplasty weren't sure whether the procedure compressed plaques, stretched vessels, or triggered a "self-healing process" (1979). Even now, Verheye et al. admit that the precise mechanism of action of coronary-sinus reduction "remains unclear."

Second, many of the procedures produced surprisingly good clinical outcomes, especially in the uncontrolled case series typical of early reports. Modern readers may dismiss such results as false positives, the result of spontaneous symptom resolution, placebo effects, physician enthusiasm, inappropriate controls, and lack of randomization. However, early researchers were not naive. Beck knew that it was notoriously difficult to judge clinical outcomes in CAD, that other surgeons would be skeptical of his techniques, and that his enthusiasm might bias his results. He deliberately adopted a "conservative point of view" and endorsed only treatments backed by experimental studies, clinical outcomes, and postmortem analyses. ${ }^{1}$ Even if his methods wouldn't pass muster today, Beck's procedures may have done something, through physiological or psychological mechanisms of therapeutic efficacy, that we don't yet understand.

The past cycles of enthusiasm and disillusionment with myocardial revascularization have produced consensus about the need for rigorous clinical research. Trials with a sham-intervention control have often been decisive, as in the case of internal-thoracicartery ligation and many procedures since (1959). There have even been calls for such trials of angioplasty for stable angina (2014). Expecting skepticism, Verheye and colleagues used sham controls and well-characterized outcomes in hopes that rigor would produce convincing results. It's too soon to know whether the revival of sinus reduction will succeed or become another of the many techniques of myocardial revascularization that have been tried and discarded.

Disclosure forms provided by the author are available with the full text of this article at NEJM.org.

From the Department of Global Health and Social Medicine, Harvard Medical School, Boston; and the Department of the History of Science, Harvard University, Cambridge, MA.

1. Beck CS. Principles underlying the operative approach to the treatment of myocardial ischemia. Ann Surg 1943;118:788-806.

2. Vansant JH, Muller WH Jr. Surgical procedures to revascularize the heart: a review of the literature. Am J Surg 1960;100:572-83.

3. Gross L, Blum L, Silverman G. Experimental attempts to increase the blood supply to the dog's heart by means of coronary sinus occlusion. J Exp Med 1937;65:91108.

4. Beck CS, Leighninger DS, Brofman BL, Bond JF. Some new concepts of coronary heart disease: results after surgical operation. J Am Med Assoc 1958;168:2110-7.

5. Brofman BL. Medical evaluation of the Beck operation for coronary artery disease. J Am Med Assoc 1956;162:1603-6.

DOI: 10.1056/NEJMp1414157

Copyright @ 2015 Massachusetts Medical Society. 